\title{
Percepção sobre o Assédio Moral na Assembleia Legislativa do Estado de Alagoas: Uma Concepção em Construção
}

\author{
Sinara Márcia de Mendonça Lopes Brasileiro ${ }^{1}$; Celina Ortiz Dávalos ${ }^{2}$
}

Resumo: Esta pesquisa visa a analisar a forma como acontece o assédio moral na administração pública no Estado de Alagoas, principalmente, na Assembleia Legislativa de Alagoas. Para tanto, foi utilizado o método de pesquisa quantitativo e o qualitativo com alcance descritivo e exploratório. A população do local é formada por funcionários públicos, efetivos, da Assembleia Legislativa de Alagoas, que atualmente é composta por 750 trabalhadores, em exercício de suas funções. No entanto, a amostra da pesquisa, composta por 150 foram funcionários que participaram do estudo, no período do ano de 2015 a 2016, selecionados de maneira aleatória, e o levantamento dos dados foi feito através de questionários. Os resultados levaram a crer que o assédio moral, na Assembleia Legislativa de Alagoas, acontece de forma sutil, por intermédio de brincadeiras, no cotidiano laboral, que são consideradas natural, em virtude da cultura local, mas, na realidade, trata-se de violências e de agressões psicológicas no ambiente de trabalho. Repercutem na vida particular e profissional do trabalhador, já que o expõem a situações vexatórias, constrangedoras, em forma de ameaças veladas, isolamentos, deixando o trabalhador ocioso, espalhando calúnias e fofocas com a intenção de denegrir a reputação das vítimas, o que gera prejuízos a sua autoestima, a sua saúde física e mental, interferindo no desempenho profissional do trabalhador.

Palavras-chave: Assédio Moral. Direitos Humanos. Direito do Trabalho. Administração Pública.

\section{Perception of Moral Harassment in the Legislative Assembly of the State of Alagoas: A Conception in Construction}

\begin{abstract}
This research aims at analyzing how bullying occurs in public administration in the State of Alagoas, especially in the Legislative Assembly of Alagoas. For that, the quantitative and qualitative research method was used with descriptive and exploratory scope. The population of the place is formed by public employees, effective, of the Legislative Assembly of Alagoas, which currently is composed of 750 workers, in the exercise of their functions. However, the research sample, composed of 150 were employees who participated in the study, during the period from 2015 to 2016, randomly selected, and the data were collected through questionnaires. The results have led one to believe that bullying in the Legislative Assembly of Alagoas happens in a simple way, through play, in daily work, which is considered natural, due to the local culture, but in reality, it is a question of violence and psychological aggression in the workplace. They affect the private and professional life of the worker, since they expose him to vexatious, embarrassing situations, in the form of veiled threats, isolation, leaving the worker idle, spreading calumnies and gossip in order to denigrate the reputation of the victims, their self-esteem, their physical and mental health, interfering in the professional performance of the worker.
\end{abstract}

Keywords: Moral Harassment. Human rights. Labor Law. Public administration.

\footnotetext{
${ }^{1}$ Maestría en Gobierno y Gerencia Pública. Universidad Americana. Facultad de Posgrado. Asuncion - PY.

${ }^{2}$ Universidad Americana. Facultad de Posgrado. Asuncion - PY.
} 


\section{Introdução}

O assédio moral caracteriza-se por um conjunto de atitudes hostis, como perseguições, humilhações, que expõem o trabalhador a situações degradantes e constrangedoras, as quais se desenvolvem por um período prolongado, gerando constrangimento, durante o tempo em que se desenvolvem as atividades cotidianas, porque se tem relações hierárquicas arbitrárias.

A Organização Internacional do Trabalho (OIT) realizou um estudo sobre a situação dos servidores que são vítimas dessa prática e concluiu que, aproximadamente, $42 \%$ dos brasileiros já sofreram assédio moral. Nesse sentido de direito e de valorização do princípio de igualdade entre as pessoas, buscam-se novas ações que possibilitem harmonia na convivência social. Inclusive, as relações de trabalho passam por mudanças estruturais, que viabilizam maior eficácia e eficiência na defesa dos interesses e dos anseios do servidor público brasileiro, logo tem buscado combater a banalização do assédio moral nas relações de trabalho. (OIT, 2015)

Com o advento do novo constitucionalismo, com a carta Magna da República Federativa do Brasil, de 1988, evidenciou maior dignidade à pessoa humana, como princípio unificador dos direitos fundamentais, como um dos fundamentos do Estado Democrático de Direito, alçando, portanto, a categoria como sendo o valor supremo da democracia.

Os objetivos do presente estudo foram: a) Analisar a forma em que acontece o assédio moral na Assembleia Legislativa do Estado de Alagoas/Brasil; b) Determinar a ocorrência e o tipo do assédio moral na Assembleia Legislativa do Estado de Alagoas; c) Estabelecer se há diferença no assédio moral sofrido entre o homem e a mulher no Poder Legislativo do Estado de Alagoas.

\section{Assédio Moral}

$\mathrm{O}$ assédio moral caracteriza-se por atitudes que causam danos psicologicos e físicos nos trabalhadores/servidores públicos, decorrentes de humilhações vivenciadas constantemente. Trata-se de uma violência que se desenvolve no ambiente laboral, expondo pessoas a situações prolongadas e repetitivas, ofensas, ridicularização pública, inferiorização, punições e ações desestabilizantes, que contribuem para a diminuição do desempenho e da qualidade de vida. Manifesta-se direta e indiretamente, sejam por acusações, insultos, fofocas, isolamento seja pela falta de comunicação, excluindo socialmente o trabalhador.

Os estudos sobre o assédio moral, como fenômeno nas relações de trabalho, tiveram início nas investigações divulgadas por Heing Leymann, pesquisador na àrea de Psicologia do Trabalho, que 
publicou uma análise científica pelo Nacional Boord of Occupational Safety and Health in Stokolm e tornou-se o primeiro a descrever, mostrar para o mundo as consequências do mobbing, dentro da neuropsiquica de pessoa sujeita a humilhações e a hostilidades no ambiente de trabalho (HIRIGOYEN, 2005).

Com o advento da Constituição da República Federativa do Brasil, de 1988 (CF/88), o assédio moral passou a ter relevância juridicamente, visto que incorporou a defesa da personalidade como um dos direitos fundamentais e legitimou o assédio moral. Contudo, o tema ainda é muito pouco discutido, mesmo a existência do fenômeno sendo em larga escala. O primeiro trabalho de pesquisa sobre humilhações no ambiente de labor foi realizado pela médica do trabalho Margarida Maria Silveira Barreto, pesquisadora da Pontifícia Universidade Católica de São Paulo (PUC-SP), na dissertação de mestrado com o tema Uma jornada de humilhações, defendida em 2000, que cuminou com a publicação do livro Violência, saúde e trabalho: uma jornada de humilhações, em 2006.

O trabalho de pesquisa dela teve como cenário o Sindicato de Trabalhadores nas Indústrias Químicas, Plásticas, Farnacéuticas, Cosméticos e Similares de São Paulo, com o estudo de casos de 1.311 homens e 761 mulheres, em que relataram uma rotina de constrangimentos e desqualificações, com demonstração de um sentimento de humilhação, que foi o eixo central da pesquisa de Barreto (20014).

Conceituando o assédio moral, Rufino (2011) entende que esse acontece quando alguém se utiliza de poderes para infringir direitos de outra pessoa através de atos desenfreados e irracionais. Assim, ficará a cargo dos preceitos legais tentar colocar limites a tais comportamentos a fim de que os direitos de outrem possam ser preservados. Enquanto trabalhador, o indivíduo necessita desse emprego para garantir a subsistência própria e da família, sendo inadmissível qualquer violação a sua honra e a sua imagem.

Desse modo, segundo Delgado (2010), é importante levar em conta o princípio da dignidade humana. Com base nisso, vem a tentativa de impor limites às condutas humanas, para tanto, o conhecimento dos princípios de razoabilidade e de racionalidade é de fundamental importância. A finalidade é fazer com que os direitos fundamentais do empregado sejam respeitados e que o contrato de trabalho seja realizado em condições justas e respeitando as pessoas que o celebram. Ao definir o princípio, os autores tendem a incorporar a noção derivada de senso comum: "a de seguir, um padrão médio de racionalidade e de razoabilidade sendo este um critério importante na análise e julgamento desses atos" (DELGADO, 2010, p. 16). A dignidade humana é um princípio, utilizado para fundamentar os direitos e as garantias básicas do homem e do cidadão, pois é através deste, que o homem firma a sua posição pessoal e social em sociedade. Portanto, o autor esclarece que qualquer tipo de conduta que fere esse princípio será caracterizado como assédio moral, passível de sanção ou punição ao agressor. 
Insista-se que, para a constituição democrática brasileira, a dignidade do ser humano fica lesada caso este encontre privado instrumentos de minha afirmação social. Enquanto ser social, a pessoa humana tem assegurada por este princípio iluminador e normativo não apenas a intangibilidade de valores individuais básicos como também um mínimo de possibilidade de afirmação no plano comunitário circundante (RUSSOMANO, 2012, p. 108).

O assédio moral é identificado como qualquer tipo de prática que viole os direitos básicos de uma pessoa, afetando suas condutas pessoais e sociais, bem como, sua autoestima a ponto de causar interferência na sua vida em sociedade.

Assim, segundo Hirigoyen (2005), o assédio moral pode ser identificado através de práticas abusivas, como ofensas, menosprezo à vítima, rebaixamento moral, interiorização, submissão e constrangimento. É uma situação grave e extremamente violenta, porque atinge diretamente o psicológico do trabalhador no local onde ele desenvolve suas atividades laborais.

Esse tipo de comportamento, além de prejudicar a dignidade da pessoa humana, ocasiona a destruição das redes de comunicação, podendo perturbar a realização do trabalho, uma vez que uma pessoa, ameaçada e coagida, não apresenta motivação para desempenhar de maneira eficaz a sua tarefa. Em muitos casos, percebe-se o isolamento, seja voluntário ou seja forçado.

No entanto, é preciso diferenciar os conflitos saudáveis do que caracteriza assédio moral. Segundo Carcalho Filho (2015), entende-se como natural aquele que surge a partir de regras e de tarefas claras, de relações com colaboração, objetivos comuns e compartilhados, organização saudável, conflitos e confrontos ocasionais, estratégias abertas e francas e conflitos e discussões abertas. Já aqueles que são assédio são as regras ambíguas, comportamentos sem colaboração/boicote, falta de previsão, relações interpessoais ambíguas, ações sem ética e de larga duração.

A vítima geralmente se sente inferior, revoltada, perturbada, traída, humilhada, mortificada ou com raiva. Essas humilhações tendem a provocar baixa autoestima, dor, tristeza e magoa nas pessoas afetadas. A relação que se desenvolve entre vítima e agressor passa a ser confusa, já que o comportamento se torna antiético. Pode-se verificar que são comportamentos hostis que ocorrem repetidas vezes, num determinado período temporal. Trata-se de uma situação crônica de violência psicológica extrema, não apenas pela intensidade das agressões, mas por sua insistência. A Organização Mundial de Saúde (OMS) oferece um quadro para diferenciar os conflitos saudáveis das situações que podem ser entendidas como assédio moral (BARRETO, 2014).

Essas situações ocorrem no local de trabalho e são decorrentes da relação trabalhista, entre pessoas que se vinculam a partir de uma relação contratual ou que sejam dependentes, direta ou indiretamente da empresa. Independemente da relação hierárquica, podendo ocorrer entre pessoas da mesma posição ou superiores contra subordinados. Inclui, também, condutas e omissões que induzem ao desconforto e ao constrangimento. 
A gravidade desses atos significa violação às condutas aceitas socialmente. Apesar de todos os conceitos enunciados anteriormente, ainda não há uma definição que traduza integralmente o que vem a ser assédio moral, porém Hirigoyen (2005, p. 37) traz um conceito sobre assédio moral no ambiente de trabalho bastante esclarecedor:

\begin{abstract}
O assédio moral começa frequentemente pela recusa de uma diferença. Ela se manifesta por um comportamento no limite da discriminação. Propostas sexistas para desencorajar uma mulher a aceitar uma função tipicamente masculina, brincadeiras grosseiras a respeito de um homossexual [...] provavelmente, da discriminação chegou-se ao assédio moral, mais sutil e menos identificável, a fim de não correr o risco de receber uma sanção. Quando a recusa de origina de um grupo, para ele é difícil aceitar alguém que pensa ou age de forma diferente ou que tem espírito crítico.
\end{abstract}

Ante o exposto, é um fenômeno antigo, pois esse vem ocorrendo desde o início da vida social e da familiar, porém sua abordagem é recente, especialmente, no que diz respeito ao mundo do trabalho. Entender bem do conceito de assédio moral é importante, pois esse tipo de conduta fere os princípios constitucionais referentes à dignidade humana. No entanto, é necessário entender que a omissão dispensada a esses fatos pode desencadear diversas consequências, às quais são consideradas gravíssimas para o bem-estar do ser humano, comprometendo as relações que se desenvolvem no ambiente de trabalho e são essenciais, não apenas para a garantia da produtividade, mas também para a saúde psicológica dos indivíduos.

\title{
Direitos Fundamentais E Convivência Social
}

De acordo com Santos (2013) a Organização das Nações Unidas para a Educação, a Ciência e a Cultura (UNESCO) conceitua os direitos fundamentais tanto como uma espécie de rede protetora institucionalizada a despeito dos excessos de poderes, quanto por regras que são determinadas para garantir condições de vida digna, dando possibilidade ao homem de se desenvolver e crescer em sociedade. Portanto, de acordo com Silva (2012, p. 178):

Os direitos fundamentais do homem constituem a expressão mais adequada a este estudo, porque além de referir-se a princípios que resumem a concepção do mundo e informam a ideologia política de cada ordenamento jurídico, é reservada para designar, no nível do direito positivo, aquelas prerrogativas e instituições que ele concretiza em garantias de uma convivência digna, livre e igual de todas as pessoas.

Os Direitos humanos são caracterizados por valores e direitos inerentes ao homem. Já os direitos fundamentais fazem parte da natureza intrínseca da pessoa humana em qualquer lugar do mundo. São direitos inalienáveis, eternos e naturalmente garantidos ao ser humano. 
Os direitos fundamentais da pessoa humana são reconhecidos e protegidos em todos os Estados, embora existam algumas variações quanto à enumeração desses direitos e à extensão de cada um deles, bem como quanto à forma de protegê-los. Esses direitos não dependem da nacionalidade ou cidadania, sendo assegurados a qualquer pessoa.

Entretanto, podem existir certos meios de proteção que as leis de um Estado criam especialmente para os seus cidadãos. Para Alvarenga (2013) é necessário realizar um paralelo entre os direitos humanos, bem como, outras expressões utilizadas como direitos naturais, direitos fundamentais e liberdades públicas. Segundo a doutrina jusnaturalista, os direitos humanos também são considerados como naturais. Referem-se ao movimento que serviu para promulgar a Declaração dos Direitos do Homem e do Cidadão, durante a Revolução Francesa e 1989. Existem diferentes conceituações para os direitos subjetivos. Alguns admitem que os direitos subjetivos estejam ligados à liberdade do indivíduo em auto se determinar, ou seja, sua liberdade individual.

De acordo com Alvarenga (2013) a expressão direitos humanos serve para designar os direitos do homem estabelecidos em nível internacional. Já os Direitos fundamentais tratam dos direitos humanos, positivados internamente, dentro dos ordenamentos jurídico-positivos estatais.

Com o reconhecimento dos direitos humanos, reconhece-se também o direito à dignidade humana. De acordo com Bonavides (2013) a dignidade é o que fundamenta o Estado Democrático de Direito. Tal dignidade concede aos homens à garantia de melhores condições de vida de acordo com a ordem de justiça social vigente.

Dallari (2014, p. 08), afirma que:

\begin{abstract}
Além disso, as pessoas humanas são todas iguais por natureza e todas valem a mesma coisa, mas cada uma tem suas preferências, suas particularidades e seu modo próprio de apreciar os acontecimentos. Por causa destas diferenças, as pessoas nem sempre estão de acordo e é preciso que existam regras regulando os comportamentos, estabelecendo o que cada um deve ou não deve fazer, o que é permitido e o que é proibido.
\end{abstract}

As desigualdades humanas são vistas como um desrespeito à dignidade e à liberdade humana. Um sistema econômico onde existam homens, mulheres e crianças, passando fome, sofrendo com a miséria e com o abandono por parte dos sistemas públicos, não é um sistema que respeita a dignidade da pessoa humana, tampouco a liberdade do indivíduo.

A fim de evitar o arbítrio de poder por parte do Estado, faz-se necessário a limitação de poderes a todas as autoridades que regem o Estado, contribuindo para que a dignidade e a liberdade humana venham a ser protegidas. Tal ideia leva-nos então a admitir a existência de um Estado de Direito e a independência do Poder Judiciário.

A dignidade da pessoa humana é uma conquista do homem através da razão e da ética através da qual todas as pessoas foram beneficiadas. A dignidade é um direito inerente a todos os homens. Desta 
forma, entende que a dignidade da pessoa humana é o primeiro pressuposto para firmar todo o Sistema Constitucional, bem como o princípio que fundamenta os direitos humanos.

De acordo com Sousa (2013), o princípio de Isonomia é um direito utilizado para garantir o equilíbrio real com o objetivo único de garantir a dignidade humana. Para que a "doutrina de proteção legal" funcione é importante que os países ricos bem como os países pobres, ajudem aos países em vias de desenvolvimento a crescerem, isto tendo por objetivo último e primeiro a garantia da dignidade da pessoa humana.

\section{Contexto Social do Trabalho no Setor Público e o uso do cargo político como instrumento de poder}

As organizações públicas, desde sua origem, foram estruturadas para favorecer determinadas posturas e comportamentos de seus servidores e gestores públicos. A organização dos órgãos públicos foi feita de forma hierárquica, com estabilidade no emprego, com diferencial e tendo um sistema de remuneração e vantagens bem rígidas. Wolkmer (2012) identifica a forma especifica e racional que a burocracia se estrutura. A burocracia, na organização, é regida por leis adminsitrativas que estabelecem regras de funcionamento, de forma prévia, delimitando a forma de ocorrência em seu âmbito. Essa possui um caráter formalista, tendo em vista que todos os atos constam previstos em normas, leis, decretos etc, visando a garantir a uniformidade na interpretação e dos resultados.

Wolkmer (2012, p. 136) entende que os partidos políticos " vivem sob o signo do poder", em que são orientados para obter poder social, ou seja, obter influencia social. Um partido volta suas ações sempre para uma meta, uma causa ou uma meta pessoal. Entende-se a causa como o programa do partido, são seus objetivos, ideiais ou materiais. Quando se trata de uma meta pessoal, pode-se dizer que se refere a privilégios ou horas para o líder e os afiliados do partido.

O autor, em comento, entende que é comum o fato da ação partidária ter por objetivo essas duas metas simultaneamente, visto que a existência do partido depende de um grupo de pessoas que possa garanti-la. Assim, a luta pelo poder seria frequentemente condicionada às honras sociais que ele proporciona.

Diante dessa percepção, os partidos para obter o poder, usam o poder econômico, a influência social e os programas para conseguir o maior número de eleitores. Logo, tem, por objetivo, a supremacia em uma comunidade ou grupo e, assim, contar com o apoio.

O partido, através de seus candidatos, utiliza os cargos em comissão, como moedas de troca para conseguir apoio político, visto que são cargos com nomeação livre e pessoal, independentemente de concurso público, são cargos regidos pela confiança entre a autoridade superior que o nomeia e quem foi designado para assumir o cargo. 
No Brasil, a presença de apadrinhados por partidos governamentais, nas empresas estatais é uma prática comum, é exigida pelos líderes, aqueles que financiaram as atividades políticas. São pessoas que apoiam a execução da estratégia de Governo, beneficiando a elite social e estão preocupadas com a manutenção de seus empregos sem se importar com os compromissos com a sociedade. Segundo Wolkmer (2012), os cargos, em comissão, têm um caráter político, pois têm, principalmente, a tarefa de manter a dominação existente, visto que a disputa por esses, em comissão, corresponde a um instrumento de poder.

Teixeira (2011) entende que a distribuição de cargos entre aliados do governo gera ou não a existência de mecanismos democráticos de controle sobre a atuação desses nomeados, mesmo com a modernização da administração pública. Nota-se que ainda persistem práticas tradicionais no dia a dia dos órgãos estatais, visto que a escolha dos ocupantes dos cargos, em comissão, é baseada na confiança em detrimento da capacitação profissional para atuar no cargo, colocando em evidencia e, em dúvida, a imparcialidade da atuação desses funcionários.

O conflito entre ocupantes de cargo em comissão (indicados) por políticos (apadrinhados), que ocupam setores estratégicos, e os servidores públicos, concursados ou efetivados é permanente.

\section{Marco Metodológico}

O estudo do tema, em análise, trata-se de uma pesquisa do tipo transversal, descritiva e exploratória, com enfoque misto, qualitativo e quantitativo.

A população foi o público alvo da pesquisa, pessoas nas quais se pretende buscar a informações e coletar dados. Na Assembleia Legislativa de Alagoas, existem, atualmente, 750 funcionários públicos efetivos, em exercício de suas funções. A amostra constou de 150 funcionários públicos, pessoas participantes do estudo, no período do ano de 2015 a 2016. A seleção dos mesmos foi por conveniência.

As técnicas utilizadas para coletar os dados foram a enquete e a observação. $O$ instrumento utilizado para a primeira foi o questionário, já o para a segunda forma foram os indicadores.

O LIPT trata-se de um instrumento para identificar o assédio moral desenvolvido por Leymann (1996), psicólogo alemão radicado na Suécia, autor de várias pesquisas que produziram um conhecimento vasto, bem como uma teoria que conceitua o processo de hostilização, as fases de desenvolvimento e as repercussões do assédio moral. Existem vários comportamentos, em média 45, os mais frequentes, nas pesquisas realizadas pelo psicólogo em ambientes clínicos. O NAQ teve como ponto de partida o LIPT por Einarsen (1997) e possui 22 itens.

Para elaborar o questionário deste estudo, optou-se por uma combinação de ambos os instrumentos partindo da interpretação de Hirigoyen (2005), que define quatro grandes categorias, quais 
sejam: a precarização das condições de trabalho, o isolamento da vítima, atentado contra a dignidade e a violência propriamente dita (verbal, física e sexual).

O instrumento final foi testado num pequeno grupo de indivíduos, ao todo dez, com o objetivo de observar a clareza e a validade do que foi colocado.

\section{Resultados}

Obtiveram-se os resultados coletados através do questionário autopreenchido, em que constam 12 questões objetivas, subjetivas e abertas, subdividas em números e letras, respondido pelos participantes da pesquisa.

Os participantes foram 57\% do gênero feminino e $43 \%$ do gênero masculino, cuja faixa etária, havia $67 \%$, com 50 anos ou mais de idade, o que demonstra que os funcionários são pessoas que estão entrando ou encontram-se na terceira idade, portanto a maioria idosa, sendo $65 \%$ casados ou vivendo em união estável, $25 \%$ são separados e $10 \%$ solteiros ou viúvos.

Quanto a formação acadêmica, 35\%, possuía curso superior completo, 30\% Ensino Médio completo; $15 \%$ estava cursando pós-graduação, $14 \%$ já haviam concluído a Pós-graduação e, $1 \%$ dos pesquisados estavam cursando Mestrado /Doutorado, ou já haviam concluído esta etapa acadêmica.

Sobre a atuação Profissional, 47\% dos funcionários eram efetivos, do Quadro de Pessoal da Secretaria da Assembleia Legislativa, sendo que desses, 41\% ocupavam o cargo de Assistente Legislativo e $12 \%$ ocupam o cargo de Auxiliar Legislativo.

Quanto ao tempo de trabalho no serviço público, $47 \%$ contava com mais de 35 anos e $12 \%$ contava á época com 30 anos no serviço público.

Sobre as condições de trabalho, observe-se os gráficos a seguir:

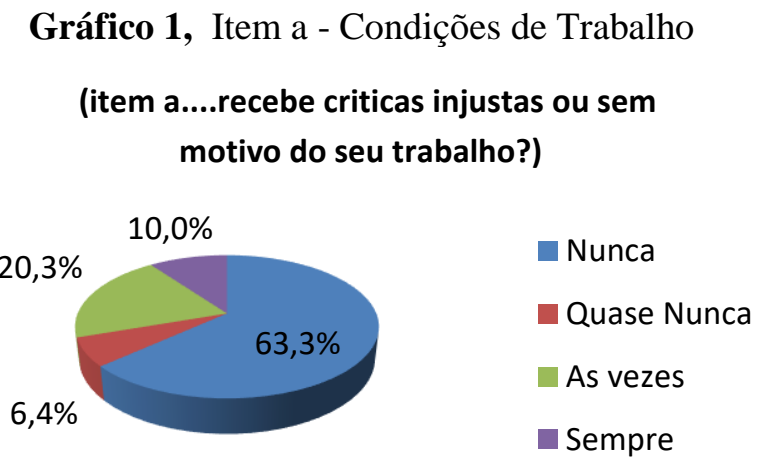

Fonte: Dados da pesquisa junto aos servidores da Assembleia Legislativa de Alagoas/Brasil, 2016. 
Neste item a, 63,3\% dos participantes da pesquisa responderam que nunca recebem críticas injustas ou sem motivo do seu trabalho; 6,4\% responderam que quase nunca recebem críticas; 20,3\% responderam que, às vezes, recebem crítica; e 10\% dos participantes da pesquisa, responderam que sempre recebem críticas injustas ou sem motivo do seu trabalho.

Gráfico 2 - Item b - Condições de Trabalho (Item b: ...já Ihe tiraram ou substituíram atividade que eram da sua responsabilidade e passadas para outra pessoa?)

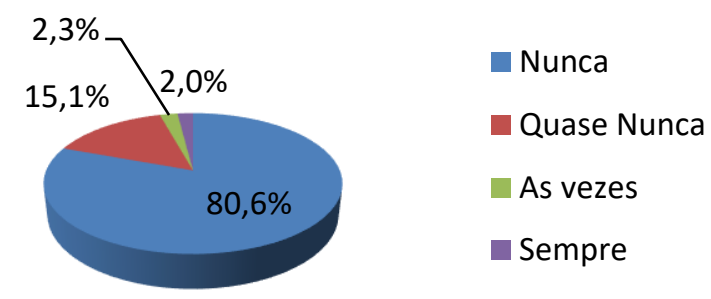

Fonte: Dados da pesquisa junto aos funcionários da Assembleia Legislativa de Alagoas/Brasil, 2016.

O gráfico 2, do item $\mathrm{b}$, demonstra a coleta de dados quanto ao fato de ter acontecido com os participantes da pesquisa, tiraram ou substituíram atividades que eram da sua responsabilidade e passadas para outra pessoa, e 80,6\% responderam que nunca tiraram ou substituíram; 15,1\% responderam que quase nunca tiraram ou substituíram; $2,3 \%$ responderam que, às vezes, tiraram ou substituíram; e $2 \%$ responderam que sempre tiraram ou substituem atividades que eram de sua responsabilidade e passam para outra pessoa.

Gráfico 3 - Item c - Condições de Trabalho (Item c: .... Lhe deixam ocioso(a), sem atividade para fazer?)

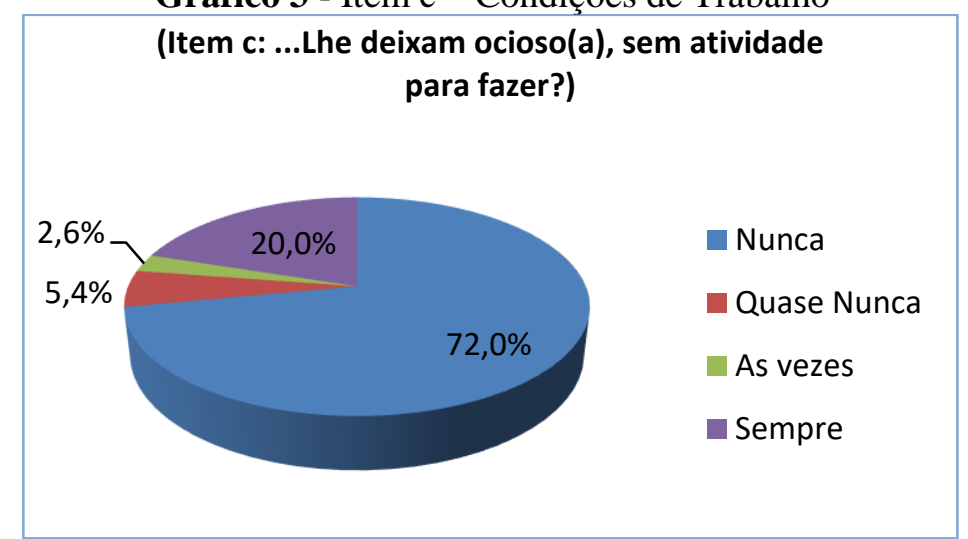

Fonte: Dados da pesquisa junto aos funcionários da Assembleia Legislativa de Alagoas/Brasil, 2016.

O gráfico 3, do item c, demostra o resultado da coleta de dados, quanto ao fato de os participantes da pesquisa ter sido deixado ocioso (a), sem atividade para fazer, e $72 \%$ responderam que nunca lhe 
deixam ocioso; $5,4 \%$ responderam que quase nunca lhe deixam ocioso; $2,6 \%$ responderam que, às vezes, deixam-lhe ocioso; e 20\% responderam que lhe deixam ocioso(a), sem atividade para fazer.

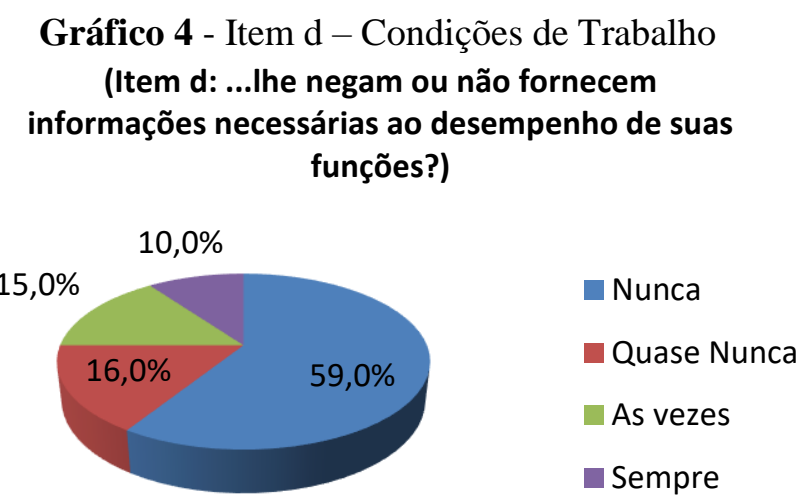

Fonte: Dados da pesquisa junto aos funcionários da Assembleia Legislativa de Alagoas/Brasil, 2016.

O gráfico 4, item d, demonstra a coleta de dados quanto ao fato de os participantes da pesquisa ter sido negado informações necessárias ao desempenho de suas funções, e 59\% responderam que nunca lhe foi negado; $16 \%$ responderam que quase nunca foi negado; $15 \%$ responderam que, às vezes, foi negado informações, e 10\% responderam que lhe foi negado ou não forneceram informações.

Gráfico 5 - Item e - Condições de Trabalho

( Item e:... recebe atividade com objetivos e/ou prazos difíceis?)

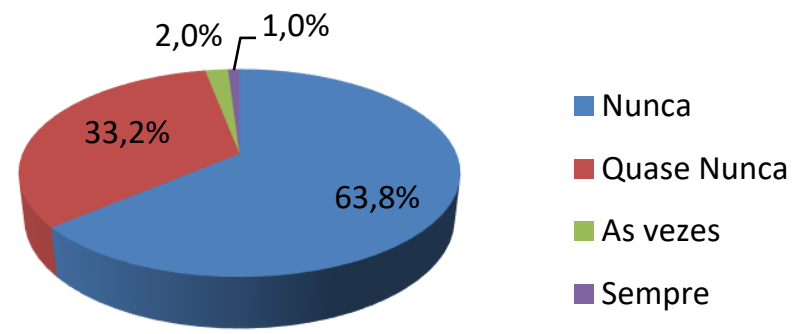

Fonte: Dados da pesquisa junto aos servidores da Assembleia Legislativa de Alagoas/Brasil, 2016

O gráfico 5, item e, demonstra que $63,8 \%$ dos participantes da pesquisa responderam nunca, recebem atividades e objetivos ou prazos difíceis; $33,2 \%$ respodenderam que quase nunca receberam; $2 \%$ responderam que, às vezes, receberam; e $1 \%$ responderam que recebem atividades e objetivos ou prazos difíceis.

A relação com os colegas foi abordada na questão de número 7, subdividida no item 7.1, que busca medir a ocorrência, frequência de algumas situações pré- determinadas nas relações com os colegas de trabalho, de posição hierárquico equivalente, superior ou inferior, relacionadas em letras a, 
b, c, d com as alternativas nunca, quase nunca, às vezes e sempre, o resultado da coleta dos dados está demonstrado no gráfico 8 , com os respectivos itens, veja-se:

Os gráficos abaixo correspondem a relação com os colegas, que se denomina de gráfico 8, com gráficos que correspondem aos itens a, b, c, d, respectivamente, para facilitar a demonstração e o entendimento dos dados coletados.

Gráfico 6 - Item a - Relação com os Colegas



Fonte: Dados da pesquisa junto aos funcionários da Assembleia Legislativa de Alagoas/Brasil, 2016

O gráfico 6, item a, busca demonstrar a coleta de dados quanto ao fato de ser permitido que colegas conversem com você e, conforme o gráfico acima, $4 \%$ responderam que nunca é permitido que os colegas conversem com você; $6 \%$ respoderam que quase nunca é permitido; $10 \%$ responderam que as vezes é permitido;80\% responderam que sempre é permitido que os colegas convercem com os participantes da pesquisa.

\section{Gráfico 7 - Item b - Relação com os Colegas}

(Item b: ....enfrenta algum tipo de hostilidade em contato com o superior hierárquico ou dos colegas?)

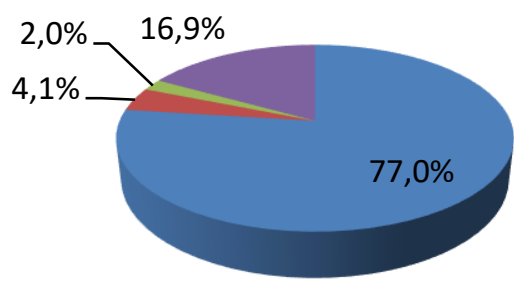

Nunca
Quase Nunca
As vezes
Sempre

Fonte: Dados da pesquisa junto aos funcionários da Assembleia Legislativa de Alagoas/Brasil, 2016

O gráfico 7, item b, demonstra o resultado da coleta de dados quanto ao fato de os participantes da pesquisa enfrentam algum tipo de hostilidade em contato com o superior hierárquico ou colega de 
trabalho e, conforme o gráfico referenciado, $77 \%$ dos participantes da pesquisa responderam que nunca enfrentaram algum tipo de hostilidade; $4,1 \%$ responderam que quase nunca enfrentaram algum tipo de hostilidade; $2 \%$ respoderam que, às vezes, enfrataram algum tipo de hostilidade, por fim, 16,9\% responderam que enfrentaram algum tipo de hostilidade em contato com o superior hierárquico ou dos colegas.

Gráfico 8 - Item c - Relação com os Colegas

( Item c : ...se sente isolado dos demais colegas?)

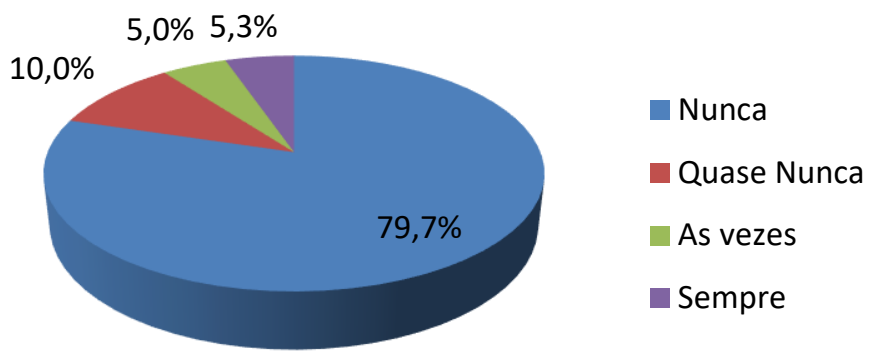

Fonte: Dados da pesquisa junto aos funcionários da Assembleia Legislativa de Alagoas/Brasil, 2016

O gráfico 8, item c, demostra o resultado da coleta de dados quanto ao fato de os participantes da pesquisa se sentir isolado dos demais colegas, e 79,7\% responderam que nunca se sentiram isolados; $10 \%$ responderam que quase nunca se setiram isolados; $5 \%$ responderam que, às vezes, setiram-se isolados, e 5,3\% responderam que se sentem isolados dos demais colegas.

Gráfico 9 - Item d - Relação com os Colegas ( Item d: ....sua presença é ignorado, os colegas ou chefe/superior hierárquico conversam entre si e não Ihe dirigem a palavra como se você não existisse?)

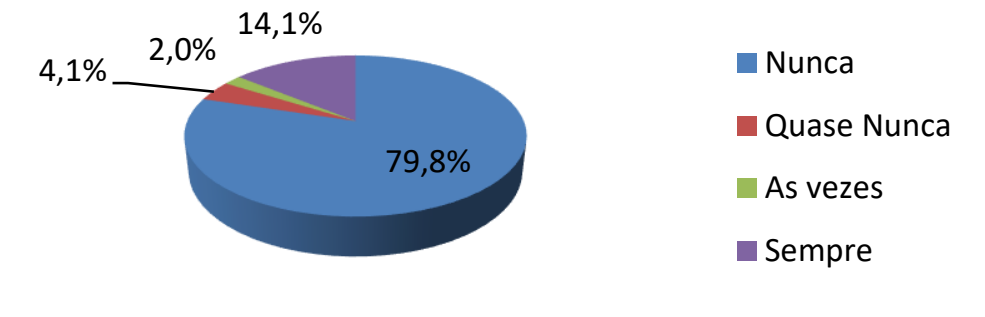

Fonte: Dados da pesquisa junto aos funcionários da Assembleia Legislativa de Alagoas/Brasil, 2016

O gráfico 9, item d, demostra o resultado da coleta de dados quanto ao fato de os participantes da pesquisa ter sua presença ignorada, os colegas ou chefe /superior hierárquico conversam entre si e não lhe dirigem a palavra como se você não existisse, e 79,8\% responderam que nunca sua presença é 
ignorada; $4,1 \%$ responderam que quase nunca foram ignorados; $2 \%$ responderam que, às vezes, foram ignorados; 14,1\% responderam que sempre são ignorados, os colegas ou chefe /superior hierárquico conversam entre si e não lhe dirige a palavra como se você não existisse.

O comportamento dos colegas foi invetigado no quesito de número 8 , que foi subdividido, para facilitar a leitura dos dados, no item 8.1, que busca medir o comportamento dos colegas de posição hierárquica equivalente, superior em relação a você, com que frequência acontece algumas situações pré determinadas relacionadas nas letras a, b, c, d, com as alternativas nunca, quase nunca, às vezes e sempre, o resultado da coleta de dados está demonstrado no gráfico 9 ,com os respectivos itens ,veja-se:

Os gráficos abaixo correspondem ao comportamento dos colegas, que denomina-se de gráfico 9, com gráficos que correspondem aos itens a, b, c, d, respectivamente, para facilitar a demonstração e o entendimento dos dados coletados.
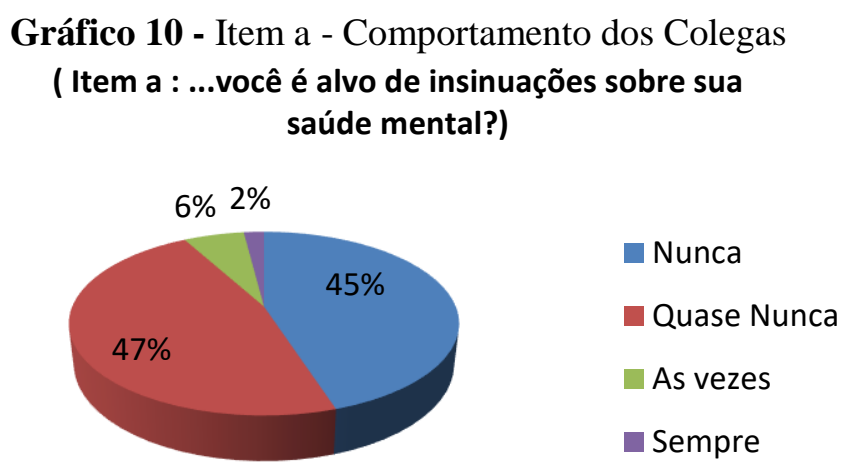

Fonte: Dados da pesquisa junto aos servidores da Assembleia Legislativa de Alagoas/Brasil, 2016

O gráfico 10, item a, demostra o resultado da coleta de dados quanto ao fato de os participantes da pesquisa ser alvo das insinuações sobre a sua saúde mental, e $45 \%$ responderam que nunca foram alvos de insinuações; $47 \%$ responderam que quase nunca foram alvos de insinuações; $6 \%$ responderam que, às vezes, foram alvos de insinuações, e $2 \%$ responderam que sempre foram alvos de insinuações sobre sua saúde mental. 


\section{Gráfico 11 - Item b - Comportamento dos Colegas \\ (Item b: ... você é humilhado(a) ou ridicularizado(a) perante outros colegas ou terceiros?)}

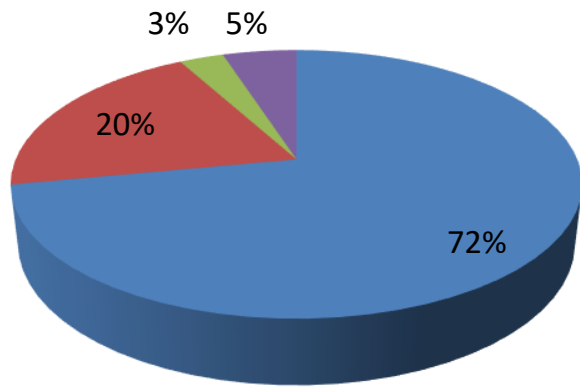

Nunca

Quase Nunca

As vezes

Sempre

Fonte: Dados da pesquisa junto aos funcionários da Assembleia Legislativa de Alagoas/Brasil, 2016

O gráfico 11, item b, demonstra o resultado da coleta de dados quanto ao fato de os participantes da pesquisa terem sido humilhados ou ridicularizados perante colegas ou terceiros, e as informações são de que $72 \%$ responderam que nunca foram humilhados ou ridicularizados; $20 \%$ responderam que quase nunca foram humilhados ou ridicularizados; $3 \%$ responderam que, às vezes, foram humilhados ou ridicularizados, e 5\% responderam que sempre são humilhados e ridicularizados perante outros colegas ou terceiros.

Gráfico 12 - Item c - Comportamento dos Colegas

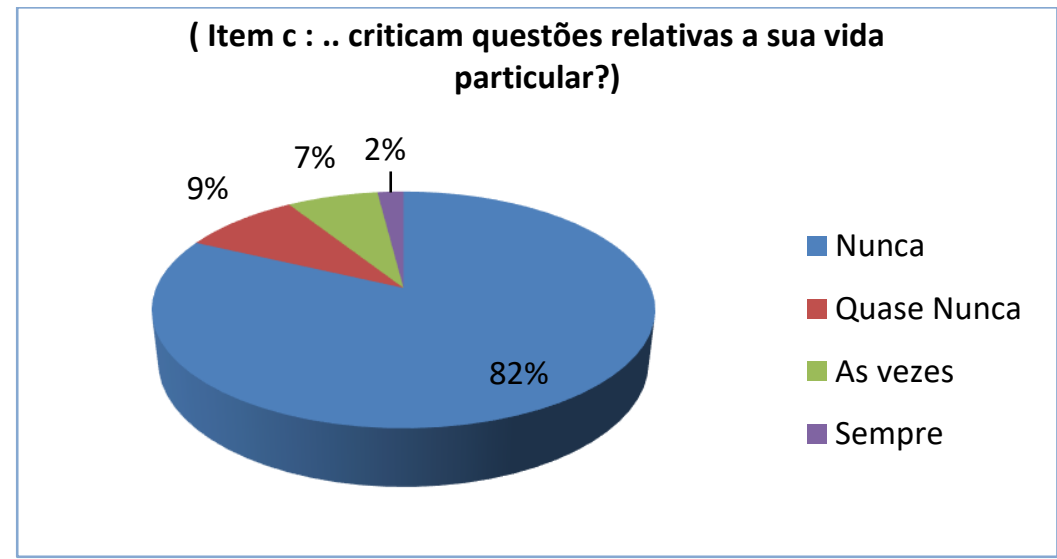

Fonte: Dados da pesquisa junto aos funcionários da Assembleia Legislativa de Alagoas/Brasil, 2016

O gráfico 12, item c, demonstra o resultado da coleta de dodos quanto ao fato de os participantes da pesquisa receberem críticas quanto às questões de sua vida particular, e $82 \%$ responderam que nunca receberam críticas; $9 \%$ responderam que quase nunca recebem críticas; $7 \%$ responderam que, às vezes, recebem críticas e $2 \%$ responderam que sempre recebem críticas quanto às questões relativas a sua vida particular. 
Gráfico 13 - Item d - Comportamento dos Colegas

( Item $d:$... você é alvo de fofocas e calúnias que buscam prejudicar sua imagem ou reputação?)
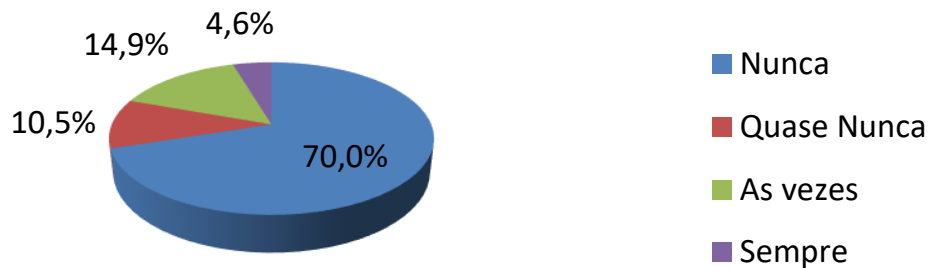

Fonte: Dados da pesquisa junto aos funcionários da Assembleia Legislativa de Alagoas/Brasil, 2016

O gráfico 13, item d, demonstra o resultado da coleta de dados dos participantes da pesquisa quanto ao fato de eles serem alvo de fofocas e calúnias que buscam prejudicar sua imagem ou reputação, e $70 \%$ responderam que nunca foram alvos; $10,5 \%$ responderam que quase nunca foram alvos; $14,9 \%$ responderam que, às vezes, foram alvos e 4,6\% responderam que foram alvos de fofocas e calúnias que buscavam prejudicar sua imagem ou reputação.

A questão de número 9 aborda as violências e as agressões sofridas pelos participantes da pesquisa, foram subdivididas no item 9.1 com situações pré determinadas relacionadas em letras a, b, c, com alternativas nunca, quase nunca, às vezes e sempre, com o resultado da coleta de dados, demonstrado em gráfico anterior com os respectivos itens, veja-se:

Os gráficos abaixo correspondem às violências e às agressões, que denomina-se de gráfico 10 , com gráficos que correspondem aos itens a, b, c, respectivamente, para facilitar a demonstração e o entendimento dos dados coletados.


Fonte: Dados da pesquisa junto aos funcionários da Assembleia Legislativa de Alagoas/Brasil, 2016

O gráfico 14, item a, demonstra o resultado da coleta de dados quanto ao fato dos particicipantes da pesquisa, por exemplo, se foi transferido de setor de trabalho isolado dos demais 
colegas, e 70,7\% responderam que nunca foram transferidos; $15 \%$ responderam que quase nunca foram transferidos; $9 \%$ responderam que, às vezes, foram transferidos e 5,3\% responderam que foram transferidos de setor de trabalho isolado dos demais colegas.

Gráfico 15 - Item b - Violências e Agressões

( Item b: ... se sentiu discriminado por se homem ou ser mulher?)

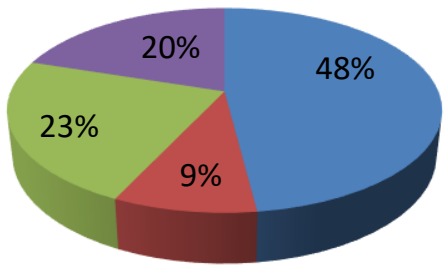

\author{
Nunca \\ - Quase Nunca \\ As vezes \\ Sempre
}

Fonte: Dados da pesquisa junto aos funcionários da Assembleia Legislativa de Alagoas/Brasil, 2016

O gráfico 15 , item $\mathrm{b}$, demonstra o resultado da coleta de dados quanto ao fato de os participantes da pesquisa se sentir discrimindado por ser homem ou mulher, e $48 \%$ responderam que nunca se sentiram discriminados; $9 \%$ responderam que quase nunca se sentiram discriminados; $23 \%$ responderam que às vezes sentem-se discriminados e $20 \%$ responderam que se sentem discriminados por ser homem ou por ser mulher.

O gráfico 16, item c, demonstra o resultado da coleta de dados quanto ao fato de os particicipantes da pesquisa já ter recebido algum tipo de ameaça, e $64 \%$ responderam que nunca receberam algum tipo de ameaça; $8 \%$ responderam que quase nunca receberam ameaças; $10 \%$ responderam que, às vezes, receberam e $18 \%$ responderam que receberam algum tipo de ameaça.

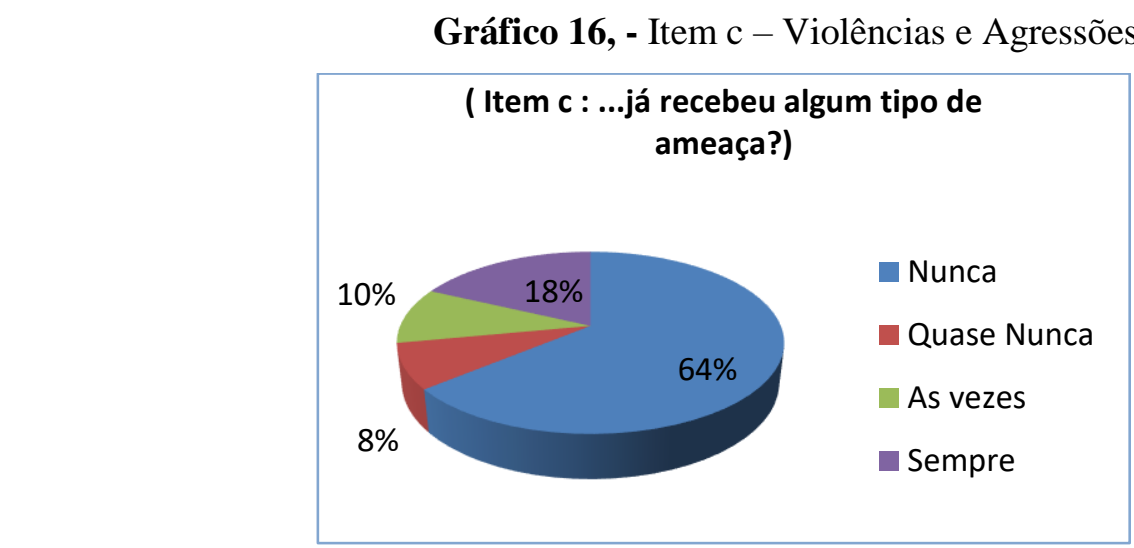

Fonte: Dados da pesquisa junto aos funcionários da Assembleia Legislativa de Alagoas/Brasil, 2016 
A questão de número 16 trata do assédio moral e foi subdividida em itens, em letras a, b, c, visando a facilitar a leitura dos dados coletados, com alternativas de sim e não, quis sejam: a) que procura saber se os participantes da pesquisa sofrem ou já sofreram assédio moral? (sim ou não) ; letra b) procura saber quem assedia? (superior hierárquico; subordinado; colega de cargo hierárquico equivalente ao seu; por fim, a letra c) que busca saber a atitude tomada quando o participante da pesquisa se sentir ameaçado e, neste item, foram relacionadas algumas situações pré-determinadas, com múltiplas alternativas, em que o resultado da coleta de dados está demonstrado no gráfico 11 , com os itens das situações mais citadas, veja-se:

Os gráficos abaixo correspondem ao assédio moral, que se denomina de gráfico 11, com gráficos que correspondem aos itens a, b, c, respectivamente, para facilitar a demonstração e o entendimento dos dados coletados.



Fonte: Dados da pesquisa junto aos funcionários da Assembleia Legislativa de Alagoas/Brasil, 2016

O gráfico 17, item a, demonstra o resultado da coleta de dados quanto ao fato de os particicipantes da pesquisa já ter sofrido ou sofre assédio moral, e 20,5\% dos participantes da pesquisa responderam que, sim, sofreram ou sofrem assédio moral, e 79,5\% responderam que não sofreram ou sofrem assédio moral.

Gráfico 18 - Item b - Assédio Moral

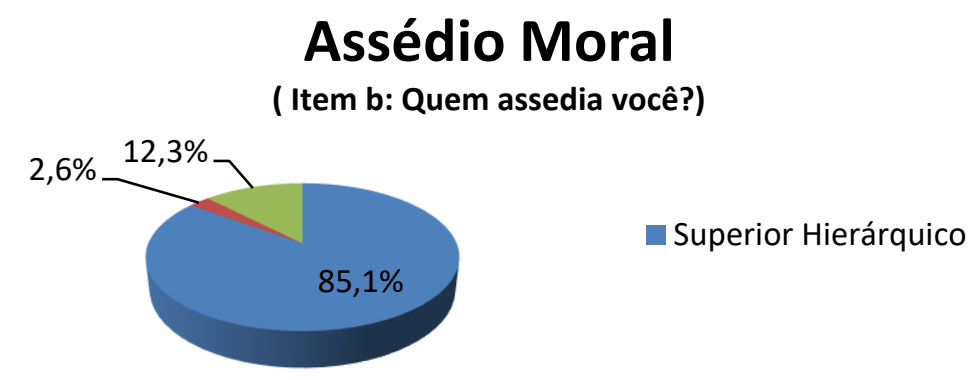

Fonte: Dados da pesquisa junto aos funcionários da Assembleia Legislativa de Alagoas/Brasil, 201 
Dos 20,5\% dos participantes da pesquisa que consideram que sofrem ou sofreram assédio moral, $85,1 \%$ apontam, como agressor, o superior hierárquico; 2,6\% apontam como agressor o subordinado e $12,3 \%$ apontam como agressor colegas de trabalho de cargo hierárquico equivalente ao seu.

A letra C, item c, da questão 19, busca informações quanto à atitude que o participante da pesquisa tomou quando se sentiu assediado, o resultado da coleta dos dados, com as alternativas mais citadas, está demonstrado no gráfico 19 , veja-se:

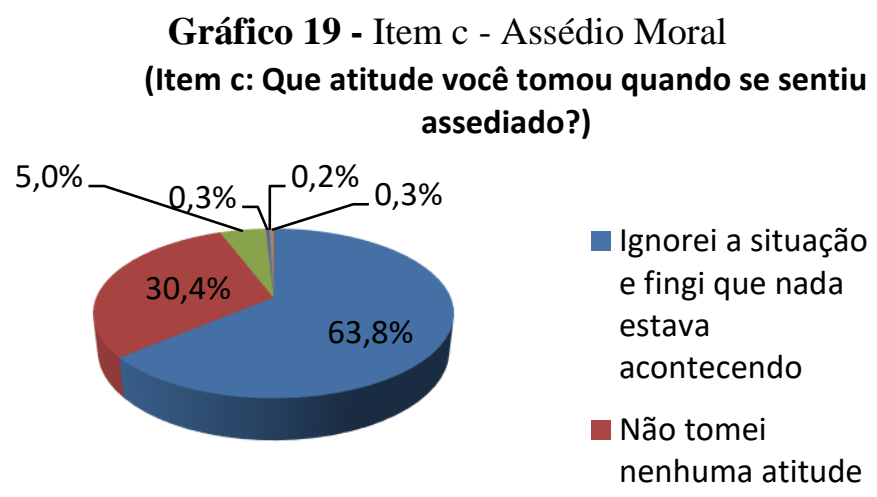

Fonte: Dados da pesquisa junto aos funcionários da Assembleia Legislativa de Alagoas/Brasil, 2016

Dos 20,5\% dos participantes da pesquisa que afirmam ter sofrido assédio moral, 63,8\% ignoraram a situação e fingiram que nada estava acontecendo; 30,4\% não tomaram nenhuma atitude ; $5,0 \%$ solicitaram transferência para outro setor; $0,3 \%$ solicitaram ajuda aos colegas de trabalho; $0,2 \%$ solicitaram ajuda ao chefe imediato e $0,3 \%$ marcaram as outras alternativas.

A questão de número 19 busca coletar dados, buscar informações, na Assembleia Legislativa de Alagoas, sendo subdividida para procura saber se existe, na instituição, órgão responsável por prevenir, coibir e punir o assédio.

O quesito de número 20 trata - se de uma questão aberta, não obrigatória, em que os participantes da pesquisa poderiam, se quisessem, relatar alguma atitude, alguma experiência do assédio moral e analisar casos que tenham ocorrido na Assembleia Legislativa de Alagoas. Em alguns relatos, os participantes da pesquisa expressam situações de hostilidades enfrentadas no ambiente de trabalho; as condições de trabalho; relação com os colegas; comportamento dos colegas; relação entre subordinados / superior hierárquico; violências e agressões, etc.

As dificuldades, situações, dentre tantas, as mais relatadas:

...cheguei para trabalhar e a fechadura da sala em que trabalhava havia sido trocada e a chave que eu tinha abria e não pude entrar e nem retirar meu material de trabalho ( Assistente Legislativo, sexo não declarado) $;$

....quando tento falar com o chefe, de maior nível hierárquico, sempre estar ao celular e sai andando, me ignora . ( Auxiliar Legislativo, sexo masculino);

....cuidado pois as paredes tem ouvidos, é melhor não falar nada. "(Analista Legislativo, sexo femenino); 
...fui pedir para despachar meu processo de enquadramento e ouvi que se eu bem soubesse do resultado da auditoria, realizada na instituição, ficaria quieto, bem quieto, pois se fosse mexer não ficaria ninguém empregado, "(Assistente Legislativo, sexo masculino);

...o chefe que assumiu agora, disse na minha cara, que eu procurasse um lugar para trabalhar pois não me queria na sala, trabalhando lá.“(Analista Legislativa, sexo não declarado);

... o chefe que assumiu o setor que trabalho é cargo em comissão, é de fora, e diz o tempo todo que os funcionários daqui são velhos, desatualizados e preguisosos, que não sabem de nada, quem não quizer ficar pode sair".(Assistente Legislativo, sexo feminino);

....estou cansado, desistimulado, não tenho vontade de trabalhar, venho por obrigação, pois nunca tem nada para fazer, tanto faz esta lá ou não:.(Assistente Legislativo, sexo masculino).

...todo dia tem uma novidade, uma ameaça, é uma incerteza de tudo, não temos paz.Parece que tudo de errado que existe na Casa é culta dos trabalhadores. "(Auxiliar Legislativo, sexo não declarado).

Com esses relatos, fica claro que ocorrem casos de assédio moral no âmbito da administração pública, na Corte Legislativa de Alagoas, bem como os índices demonstrados pelos gráficos referenciados, com os resultados da coleta de dados da amostra da pesquisa.

\section{Resultados da observação}

Como se vê, a observação é um elemento básico, na pesquisa científica, visto que é um ato de apreender coisas, acontecimentos , comportamentos e atributos pessoais e interrelações concretas, em que se procura analisar os indicadores de resultados que expressam, direta ou indiretamente, os objetivos específicos deste estudo de pesquisa, quais sejam: determinar a ocorrência e o tipo do assédio moral na Assembleia Legislativa de Alagoas; Estabelecer se há diferença no assédio moral sofrido entre homem e mulher; Identificar os instrumentos para prevenir, coibir, punir o assédio na Instituição e os indicadores de impacto que correspondem ao objetivo geral deste estudo, qual seja, analisar a forma em que acontece o assédio moral naquela Casa Legislativa.

Durante anos, sempre foram relatados, pela imprensa local e nacional e nas redes sociais, por funcionário inativo do Parlamento Alagoano, casos de constrangimentos, casos de ociosidade de funcionário, violências e agressões psicológicas, que afetavam a autoestima, saúde física e mental, por vezes, financeiras desses; fatos estes que chamavam a atenção, incomodavam e despertavam a curiosidade sobre tal fenômeno.

No período de realização deste trabalho de pesquisa, para reunir os dados, a observação foi utilizada, como método científico, em média 30 vezes, nos diversos Departamentos daquela Casa Legislativa, em seu dia a dia, nos corredores daquela unidade de administração e, em especial, no Departamento de Recursos Humanos e ainda nos resultados dos dados coletados através do questionário aplicado aos participantes da pesquisa. 


\section{Contexto da observação.}

Ao acompanhar o fenômeno do assédio moral na Assembleia Legislativa de Alagoas, procura-se identificar, selecionar o que o torna mais importante e significativo, partindo de intenções específicas, procurando extrair informações sobre o tema em estudo, através da análise de comportamentos espontâneos, as percepções de atitudes não verbais e o realismo deste fenômeno, bem como a observação, análise do resultado da coleta de dados, através do questionário aplicado aos participantes da pesquisa, exposto nos gráficos com os itens referenciados, os percentuais demonstrados.

\section{Determinação da ocorrência e o tipo do assédio moral na Assembleia Legislativa de Alagoas}

Observa-se que a ocorrência do assédio moral se dá no cotidiano da Instituição e se caracteriza por situações que, na maioria das vezes, por causa da cultura, são consideradas como naturais. Contudo, na realidade, tratam-se de violências e agressões psicológicas sofridas pela vítima, no ambiente de trabalho, de forma sutil. Em alguns casos, sob forma de brincadeiras, que se manifestam em diversas formas. Por exemplo: - Críticas injustas e sem motivo ao trabalho desenvolvido; - Deixar a vítima do assédio moral ociosa sem atividades para desenvolver durante o expediente de trabalho; - Enfrentar hostilidade no contato com o superior hierárquico ou com colegas de trabalho; - Ficar isolado; - Ter a presença ignorada; - Ser alvo de fofocas e calúnias e insinuações que buscam prejudicar sua reputação; etc.

Quanto ao tipo de assédio moral existente na Assembleia Legislativa de Alagoas, de acordo com os índices apurados, através da coleta de dados, na amostra da pesquisa, observa-se que os tipos mais evidentes são:

- O assédio moral vertical descendente, que se caracteriza por violências/agressão psicológicas, transvestidas, em virtude do entendimento cultural, de um comportamento normal, corriqueiro, sem importância, praticadas pelo superior hierárquico ou por colegas de trabalho, através de situações veladas; como ignorar a presença dos funcionários; como deixá-lo (a) ocioso(a), minando a autoestima desse, desmotivando-o, deixando-o sem vontade de trabalhar, de querer desenvolver algum projeto ou, até mesmo, de estar na instituição, pois não são valorizados, reconhecidos, o que provoca a falta de motivação;

- O assédio moral vertical ascendente que é praticado por grupos de funcionários contra o superior hierárquico, chefes, líderes de equipe de trabalho, através de situações constrangedoras, colocando dificuldades para o desempenho das atividades profissionais, com o intuito de desestabilizar, dificultar o desempenho do líder; 
- O assédio moral horizontal que é praticado pelos colegas de mesmo nível hierárquico da vítima, que buscam se destacar no ambiente de trabalho, gerando individualismos e comportamentos grosseiros, desmerecendo colegas de trabalho, minando a autoestima dos mesmos.

Observa-se o que é descrito por Martins (2015) como gestão do terror , quando as Instituições implantam uma política gerencial ultrapassada e truculenta, que recai sobre a autoestima, intimidades, saúde física, psicológica e financeira dos trabalhadores, de forma não individualizada, descentralizada no ambiente de trabalho e denominado como assédio ambiental; assédio institucional; esclarecido pela jurisprudência e pela doutrina pátria, o assédio institucional como assédio moral coletivo, visando, no contexto atual, a forçar os funcionários, conforme dados demostrados no gráfico de número 6, a maioria da amostra em estudo, tem mais de 30 anos ou 35 anos a mais de tempo de serviço, a uma aposentadoria e frear processos administrativos com pedidos diversos de regularização de direitos dos funcionários tais como: isenção da contribuição previdenciária; isenção da contribuição de imposto de renda ; verbas indenizatórias; promoção e progressão na carreira profissional e etc.

\section{Percepção da diferença no assédio moral sofrido entre o homem e a mulher na Assembleia Legislativa de Alagoas.}

Observa-se, no período da pesquisa, que o assédio moral, naquela Instituição e, certamente, em outras instituições, tanto públicas como privadas, causa prejuízos físicos, psicológicos e financeiros, tanto ao homem trabalhador quanto à mulher trabalhadora, visto que, devido à cultura e à visão de poder, próprios da região, a instituição implanta uma política de gerência ultrapassada e truculenta, uma gestão de terror, violando a reputação, a dignidade da pessoa humana e intimidade dos trabalhadores, pois se trata de prática não individualizada à vítima, tendo em visto que recai sobre todos os trabalhadores da instituição, no ambiente de trabalho.

É uma prática descentralizada que atinge todos os trabalhadores, de forma que alimenta o medo, a insegurança, com ameaças veladas e públicas que impõem a lei do silêncio.

Além dos tipos citados acima, relativos ao fenômeno de assédio moral, vale registrar que a mulher, como em todas as carreiras profissionais, está mais vulnerável a essa violência. Observa-se que desenvolvem atividades secundárias na Instituição. Atualmente, a grande maioria dos cargos de Direção, naquela Casa Legislativa, é ocupada por homens. Verifica-se, ainda, que os assédios morais, mais frequentes, além do assédio moral institucional, sofrido pelas mulheres, na instituição, são: - Calúnias e fofocas que buscam afetar sua imagem e sua reputação; - Ficam ociosas, sem atividades no expediente de trabalho; - A hostilidade dos superiores hierárquicos; - Ocupam os mesmos cargos dos homens, com 
as mesmas atribuições, com a mesma carga horária, mas recebem remunerações inferiores e são pouco prestigiadas, valorizadas pela instituição.

Observa-se que o assédio moral, além do assédio moral institucional, sofrido pelo homem, naquele local, caracteriza-se: -Pelo isolamento; -Ficam ociosos, sem atividades; -A hostilidade dos superiores hierárquicos.

Tais situações, na maioria das vezes, como em outros órgãos da administração pública, geram danos psicológicos e físicos irreparáveis, vez que mimam a autoestima e levam a vítima ao afastamento das atividades profissionais; ao desânimo e à falta de estimulo para desenvolver qualquer tipo de atividade nas instituições. Vale salientar também que as vítimas do assédio moral são pessoas comprometidas, competentes e questionadoras, com capacidade de trabalho muito grande que mesmo abaladas emocionalmente, têm qualificação profissional e são criativos.

Em resumo, uma análise da forma como acontece o assédio moral na Assembleia Legislativa de Alagoas, observou-se que o assédio moral na administração pública, como também em diversas instituições privadas, assume a forma de ações cotidianas, no dia a dia da Instituição; de condutas abusivas (gestos, comportamentos, atitudes) que, de forma intencional e frequente, atingem a dignidade da pessoa humana, a saúde física, psicológica e financeira dos trabalhadores, ameaçando seu emprego e desagregando o ambiente de trabalho. $\mathrm{O}$ assédio moral naquela Casa Legislativa, como em tantas outras instituições, assume tanto a forma de ações diretas (acusações, insultos, gritos, humilhações públicas) quanto à forma indireta (propagação de boatos, isolamento, recusa na comunicação, fofocas e calúnias que buscam prejudicar a imagem ou reputação e a exclusão social dos trabalhadores), conduta psicológica repetitiva.

O terror psicológico, psicoterror, violência psicológica são outras nomenclaturas dadas ao assédio moral, que tem por finalidade excluir a vítima do ambiente de trabalho.

Dentre as forma de assédio moral mais relatadas pelos funcionários/servidores da Instituição escolhida para a pesquisa do tema em apreço, assim como em outras Repartições Públicas, são: Instruções confusas e imprecisas ao (à) trabalhador (a); Dificultar o trabalho; Ignorar a presença do (a) trabalhador (a), ou não cumprimentá-lo (a) ou, ainda, não lhe dirigir a palavra na frente dos outros, deliberadamente; Fazer críticas ou brincadeiras de mau gosto ao (à) trabalhador (a) em público; Ameaças; Isolamento; Insultos; Propagar calúnias e fofocas que buscam prejudicar a imagem e reputação do (a) trabalhador (a); Deixar o (a) trabalhador (a) ocioso (a), sem atividades no horário do seu expediente; Hostilidade do superior hierárquico; Dificultar, procrastinar o acesso dos trabalhadores aos direitos previstos em Lei.

Tais formas de assédio moral têm por objetivo desestabilizar emocional e profissionalmente o indivídio, fazer com que a vitíma se sujeite passivamente a determinadas condições de humilhação e 
constrangimento; a más condições de trabalho; não reivindique direitos; não questione; não solicite providências e etc., sem contar com os prejuízos psicológicos, físicos e financeiros ao trabalhador.

\section{Considerações finais}

Este estudo teve por objetivo geral analisar a forma em que acontece o fenômeno do assédio moral na administração pública, na Assembleia Legislativa de Alagoas.

O tema em apreço é complexo, porquanto fica evidente as limitações conceituais presentes, através de análises superficiais ou precipitadas, como também em estudos mais substanciados, que revelam os aspectos marcantes do processo de assédio moral, o que faz parte de uma sequência social, o que envolve diversos mediadores, o que dificulta seu desvendamento.

Como se viu, o assédio moral é uma relação que envolve vários fatores, dentre eles a figura de um "assediador "e a figura de uma "vítima" (assediado). Como em outros estudos sobre o tema existe uma lacuna, na escuta do "assediador", que apesar dos esforços para tentar preenche-la ela permaneceu na pesquisa, devido a não aceitação dos gestores em participar, respondendo ao questionário aplicado.

Com relação a analisar a forma em que acontece o assédio moral na Assembleia Legislativa, conclui-se que a forma como acontece assédio moral, naquela Casa Legislativa, são através de ações cotidianas da instituição; de condutas abusivas ( gestos , comportamentos, atitudes) ; de forma intencional e frequente, atingem a dignidade da pessoa humana , a saúde física e psicológica ; de forma direta (acusações, insultos, gestos, humilhações públicas); de forma indireta ( propagação de boatos, isolamento, recusa na comunicação, fofocas e calúnias que buscam prejudicar a imagem ou reputação e a exclusão social dos servidores ; o terror psicológico, formas que buscam desestabilizar emocionalmente e profissionalmente o indivíduo, sujeitando-o à humilhações e constrangimentos,tornando-o passivo e sem questionar, tendo em vista a cultura predominante de submissão e a visão de normalidade diante do delito praticado.

Quanto a determinar a ocorrência e o tipo do assédio moral na Assembleia Legislativa de Alagoas, observou-se que ocorrência do assédio moral naquela instituição se dá no cotidiano, e se caracteriza por situações que na maioria das vezes, em virtude da cultura, são consideradas como normais. Quanto ao tipo de assédio moral praticado naquele Poder Legislativo, conforme os resultados dos dados coletados, os tipos mais relatados pelos servidores públicos são: a) o assédio moral vertical descendente onde o agressor é o superior hierárquico ,com atitudes autoritárias, desumanas e o e ascendente onde o agressor é um grupo de subordinados ;b) o assédio moral horizontal ( simples e composto) onde o agressor é um ou mais colegas de trabalho do mesmo nível hierárquico da vítima; c) 
a gestão pelo terror ou psicoterror, descrito na bibliografia como gestão do terror , fruto de uma política gerencial ultrapassada e truculenta que recai sobre a auto estima dos servidores.

Sobre se estabelecer se há diferença no assédio moral sofrido entre o homem e a mulher naquele Poder Legislativo, observou-se que a prática do fenômeno em estudo não é individualizada à vítima, é descentralizada e recai sobre todos os servidores da instituição, no ambiente de trabalho, pois é alimentado pelo medo, pela insegurança, com ameaças veladas e públicas que impõem a lei do silêncio e violências psicológicas que desestabilizam física e psicologicamente o trabalhador.

A mulher, como nas outras instituições públicas e/ou privadas, está mais vulnerável a prática do delito de assédio moral, pois desenvolvem atividades secundárias , visto que a grande maioria dos cargos de Direção da estrutura administrativa daquela instituição é ocupada por homens e tem salários inferiores ,embora ocupando os mesmos cargos , desenvolvendo as mesmas atividades, e com as mesmas atribuições , além de ser vítima de calúnias e fofocas que buscam afetar sua imagem e sua reputação.

Diante disso, ressalta-se a necessidade de estudos que comtemplam a escuta do assediador para melhor compreensão do assédio moral, visto que, na maioria das vezes, ocupam cargos gerenciais, por indicação política (apadrinhados por políticos), e também estão bastante vulneráveis e pressionados pelos superiores hierárquicos e pelos colegas de trabalho.

Os abusos, na gestão na administração pública, servem como ferramenta que impulsiona os sentimentos negativos, como rivalidade, inveja, ciúme e medo. São sentimentos próprios dos seres humanos, quando estimulados pela pressão, opressão e competitividade nas relações de trabalho que levam o indivíduo a praticar ações perversas, como assediar moralmente outrem.

\section{Referências}

ALVARENGA, Lúcia Barros Freitas de. Direitos Humanos e erradicação da pobreza: uma dimensão hermenêutica para a realização constitucional. Brasília: Brasília jurídica, 2013.

BONAVIDES, Paulo. Curso de direito constitucional. São Paulo: Malheiros, 2013.

CARVALHO FILHO, José dos Santos. Manual de Direito Administrativo. 28 ed. São Paulo: Atlas, 2015.

CAVALIERI, Lindomar. Direito do Consumidor. São Paulo: Unesp, 2011.

CAVAliERI FILHO, Antônio Carlos de Araújo. Teoria Geral do Processo. 10.ed. São Paulo: Malheiros, 2011.

COUTO, Reinaldo. Curso de Direito Adminsitrativo. São Paulo: Saraiva, 2015. 
DALLARI, Dalmo de Abreu. Elementos da teoria geral do Estado. $21^{\mathrm{a}}$ edição. São Paulo: Saraiva, 2014.

DELGADO, Maurício Godinho. Curso de Direito do Trabalho. São Paulo: LTR, 2010.

EINARSEN, Stale et al. The concepto f bullying at work. In: El-NARSEN, Stale et al. Bullying and emotional abuse in the workplace: international perspectives in research and practice. Londres e Nova York: Taylor \& Francis,2003.

HIRIGOYEN, Marie-France. Assédio Moral: a violência perversa do cotidiano. 7.ed. Rio de Janeiro: Bertrand Brasil, 2005.

LEYMANN, Heinz. The contempt and development of mobbing at work. European Journal of Work and Organizational Psychology, Peter Herriot,1996.

MARTINS, Sérgio Pinto. Assédio moral no emprego. $4^{\mathrm{a}}$ edição. São Paulo:Atlas,2015

RUFINO, Regina Celia. Direito do Trabalho. São Paulo: UNESP, 2011.

RUSSOMANO, Mozart Victor. Comentários à Consolidação das Leis do Trabalho. Rio de Janeiro: Forense, 2012.

SANTOS, Antônio Jeová da Silva. Dano moral indenizável. São Paulo: Método, 2013.

SILVA, Jorge Luiz de Oliveira da. Assédio Moral no Ambiente de Trabalho, $2^{\mathrm{a}}$ edição, Revista, Ampliada e Atualizada-São Paulo: Livraria e EdtoraUniversitária de Direito,2012.

SOUSA, André Salgado Matos. Direito Administrativo Geral. São Paulo: Atlas, 2013.

TEIXEIRA, Sálvio de Figueiredo. Dano moral e erro médico. São Paulo: Saraiva, 2011.

WOLKMER, Antônio Carlos. Introdução ao pensamento jurídico crítico. Editora Saraiva. 2012.

\section{Como citar este artigo (Formato ABNT):}

BRASILEIRO, Sinara Márcia de Mendonça Lopes; DÁVALOS, Celina Ortiz. Percepção sobre o Assédio Moral na Assembleia Legislativa do Estado de Alagoas: Uma Concepção em Construção. Id on Line Rev.Mult. Psic., 2018, vol.12, n.41, p.911-936. ISSN: 1981-1179.

Recebido: 25/07/2018.

Aceito: $27 / 07 / 2018$ 